\section{Dealing with imposter syndrome}

Judy Robertson
Do you feel like a fraud?

Do you secretly think that you know less than your colleagues and that it is only a matter of time before you get found out? If so, you may have fallen prey to imposter syndrome. And you're not alone. Imposter syndrome, characterised by "persistent thoughts of intellectual phoniness" (Hutchins \& Rainbolt, 2016), is common in high performers across a range of careers. Graduate students, early career researchers, women, and minority groups suffer from it. But you know what? So do professors and so do men (Hutchins \& Rainbolt, 2016; Woolston, 2016). When you think about it, it's not that surprising that so many academics are wracked with self-doubt.

Academia is a high-pressure environment with too many people competing for limited resources and where performance is measured against ridiculously high standards. To be an academic - even a successful one - is to live with regular rejection from reviewers, journal editors, promotion committees and grant funding panels. The continual cycle of trying one's best, being rejected in highly competitive circumstances and then mustering the strength to try once more is draining.

Imposter syndrome provokes anxiety and stress, and can lead people to give up their academic careers because they feel they are not good enough (Woolston, 2016). This is unfortunate because people in this position are often highly talented when considered objectively: they are their own worst critics.

However, imposter syndrome can cause people to underperform despite their talent, for example by micromanaging their team, by delaying making decisions, by procrastinating, or by insisting that all tasks must be done perfectly rather than prioritising (Mount \& Tardanico, 2016).

It is important for managers to recognise that different groups may experience imposter syndrome differently. It is likely to be more common among staff vulnerable to stereotype threat, often women and minority groups, (Dasgupta, 2011). Women and men may employ different coping mechanisms. In particular, men may be more prone to maladaptive coping strategies which could lead to health problems (Hutchins \& Rainbolt, 2016). Here are some ways we can overcome imposter syndrome by taking care of ourselves and our colleagues.

\section{Ingredients}

- Empathy (as a manager) and appreciation.

- Self-awareness and introspection.

- Accurate feedback on your performance.

- A mentor or peer with whom you identify.

- Understanding of imposter syndrome. 


\section{Method}

1. Look out for what triggers imposter syndrome for you so that you can avoid or prepare for such situations in the future. In a qualitative criticalincident analysis of how academics are affected by imposter syndrome, Hutchins \& Rainbolt (2016) identify a series of events which trigger or revive persistent feelings of inadequacy:

- $\quad$ Questioning expertise. "Do I know enough? Do I belong here?" and questions triggered by conversations with colleagues who appear to be much more knowledgeable, or who are rude enough to tell you that you are wrong. In my experience there will also generally be a few top-of-theclass students who are perfectly happy to comment on how wrong you are, in public or in earnest after-class conversations. It's not surprising that you can start questioning yourself, particularly in situations of stereotype threat.

- Comparisons among colleagues. "Why is everyone doing so much better than I am? I'll never measure up." In my view, the Research Excellence Framework (REF) really stirs this up. During the week I wrote this recipe, our college conducted an "REF readiness" exercise. This required staff to enter all their publications and evidence of other scholarly superpowers onto a database so the outputs could be counted. This database feeds public facing web pages so it is very easy to see your colleagues' achievements and equally easy to worry that your performance is being evaluated negatively against others'. In fact, new proposals for restructuring the REF are intended to have a more collegiate setup where everyone contributes to the pool of papers for the entire department. Logically, the success of others should be no threat to you. But imposter syndrome is not logical.

- Scholarly productivity. "Will I ever get this paper finished? What will the reviewers say? Aaargh, look what the reviewers said." The pressure to produce high quality work can lead to performance anxiety and writer's block.

Expectations (in research, teaching and admin) have to be fulfilled, particularly for those on probation like the Chancellor's Fellows at Edinburgh or new lecturers, and much effort can be expended on high stakes grant applications and papers. Many tears can be shed 
over the brutal rejections of those applications and papers. If you want more proof of this, have a look at the Tumblr site "Shit my reviewers say" (https://shitmyreviewerssay. tumblr.com/) and marvel.

- Experiencing successes. As if all these triggers were not enough, by some perverse twist of psychology, some people find that experiencing success triggers imposter syndrome. Some people squirm when introduced as an expert, others worry that they will not be up to the challenge of managing a grant or assuming a more senior role.

Among this woeful catalogue of triggers, the women in Hutchins \& Rainbolt's study were more prone to worries resulting from peer comparison and harsh reviews. The men spoke about it in more general terms, although they did mention being labelled an expert in the media as a trigger. I am sure this problem would crop up for women too, if there were more opportunities to appear in the media as experts in their field rather than wearers of pretty dresses.

2. Own your successes. People with imposter syndrome are often reluctant to attribute success to their own abilities, preferring to say that they were just lucky, or they just worked hard. While modesty is a virtue, failure to acknowledge your own success is self-defeating. It can be very valuable to learn to take the time to acknowledge your success and consider what skills led to it so that you can build on this for the future. Mount \& Tardanico (2016) suggest setting a timer for five minutes and writing down ten things you do well. If you find this difficult, ask a trusted friend or colleague to help you. Reflect on these skills to see if you can identify a common factor and then consider which future roles would benefit from such a skill set.

3. Remind yourself of the facts. Imposter syndrome thrives on half-conscious misperceptions about your lack of success and what it takes to succeed. It is worth taking some time to challenge these beliefs next time you notice them surface. For example, if you find yourself thinking: "I could never be a professor because professors all speak perfect BBC English" challenge yourself to collect examples of professors with regional accents. If you think: "'Ill never be able to do this", remind yourself of the last time you achieved something similar. It is possible to use the offensively superlative descriptions in the REF to your favour here. If you know what your papers were rated at through internal 
peer review then you can use this as a way to describe your work to yourself. According to the REF 2014 assessment criteria (http://www.ref.ac.uk/panels/ assessmentcriteriaandleveldefinitions/), papers which are rated as one-star are considered to be of "Quality that is recognised nationally in terms of originality, significance and rigour". Two-star is "recognised internationally", three-star is "internationally excellent" and four-star is "world-leading". It amuses me that internationally recognised papers only get two stars in this ranking scheme. Outside academia, international recognition would be something to aspire to, not to give half marks to! At any rate, try telling yourself: "According to a panel of subject experts, my work is nationally/ internationally recognised/excellent/ universe beating". Changing to this way of thinking gave me confidence to apply for my current post.

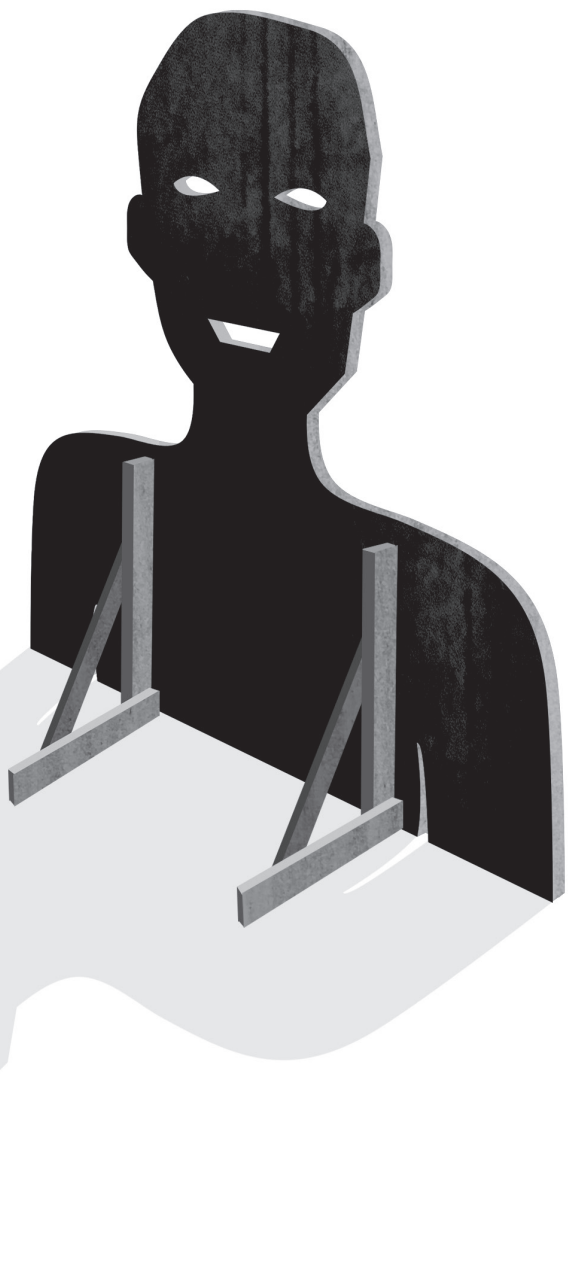


4. Talk to yourself kindly. Get in the habit of positive self-talk rather than mentally running yourself down. The women academics in the Hutchins \& Rainbolt (2016) study found that they had to remind themselves over and over again of achievements which made them proud. Think of the range of things you have achieved and why they matter. I like to save emails and cards from students to remember that when I am a teacher or a mentor I make a difference to people's lives. Some of the women in the study liked to remind themselves of their successes in other areas of their lives when they feel their confidence drain. Last week when I had a paper rejected, my family were surprised to witness me stop brooding in order to blurt out "Well, at least I can grow lemons!". I understand that not everyone takes comfort from citrus fruit farming, but there is robust empirical evidence that even short exercises in self-affirmation such as writing about the values which are most important to you can protect you from stereotype threat over a surprisingly long period (Cohen et al., 2009).

5. Find social support. Talking to a trusted colleague, mentor or coach may help. You may be surprised to learn that some of your peers have similar difficulties and would appreciate reciprocal support. Ask the person you confide in to help you acknowledge your strengths and objectively evaluate whether your limitations are as crippling as you think they are (Mount \& Tardanico, 2016). You could arrange to meet each other at potential trigger points, such as helping each other to read grant reviews or prepare keynote talks.

6. What to avoid. Some academics develop maladaptive coping strategies which are counter-productive in the long run. A common and understandable response to imposter syndrome is to work harder and longer. But there is longer term risk of workaholism which is associated with a range of health problems such as burnout, stress, insomnia, work-life conflict and poor job satisfaction (Hogan et al., 2016).

7. If you're a manager, be aware of and address the potential impact of imposter syndrome among your staff. Imposter syndrome can lead to anxiety and stress, and in some cases reduced work performance and burnout through workaholism (Mount \& Tardanico, 2016). You could well have members of staff in your team who suffer from imposter syndrome, but who are unwilling to admit it to you. This underlies the importance of making sure that all your staff know that you value their work across the spectrum of different academic activities, nourishing them "when you reward or recognise 
their good work, encourage them or offer emotional support" (Amabile \& Kramer, 2012, p. 33). I also believe that as the university places strain on staff to fulfil REF obligations, managers have a responsibility to help their staff through it by reducing anxiety and offering support. Minimising circumstances where staff feel they are under obvious pressure from social comparison could help. Another useful avenue for this is social support with colleagues. Mentors and peers who belong to the same ingroup can "socially vaccinate" against negative self-perceptions if the staff member identifies with them (Dasgupta, 2011). For example, a new female lecturer would benefit from mentoring from a senior female academic particularly in disciplines where women are in the minority. This can be hard to achieve without overburdening the few existing female staff with additional mentoring roles, but it may be possible to trade across discipline boundaries where the gender mix is the opposite (e.g. engineering with education). Mentoring and positive role models are particularly beneficial for those entering academia, and those at transition points in their career (Dasgupta, 2011).

As Amabile \& Kramer observe: "Although nourishers may matter more to some people than others, none of us can truly thrive without them" (2012, p. 33). 